\title{
Towards a definition of multiple and complex needs in children and youth: Delphi study in Flanders and international survey
}

\author{
Helena Van den Steene ${ }^{1,2}$, Dirk van West ${ }^{1,2,3}$, Inge Glazemakers ${ }^{1,2}$ \\ ${ }^{1}$ Collaborative Antwerp Psychiatric Research Institute - Youth, University of Antwerp, Belgium \\ ${ }^{2}$ University Centre for Child \& Adolescent Psychiatry (ZNA-UKJA), University of Antwerp, Belgium \\ ${ }^{3}$ Faculty of Psychology and Educational Sciences, Dep. of Clinical and Lifespan Psychology (KLEP), \\ Free University Brussels, Belgium
}

*Corresponding author: helena.vandensteene@uzbrussel.be

\begin{abstract}
Background: Multiple and complex needs $(\mathrm{MCN})$ in children and youth jeopardize their development and pose significant challenges to the different professionals they meet. However, there is no agreed-upon definition of this vulnerable population. Objectives: To develop a definition of ' $\mathrm{MCN}$ in children and youth' that is meaningful for all professionals involved in care delivery for this population.

Method: A cross-sector, multidisciplinary, and geographically spread panel of 47 experts representing mental health, youth care, juvenile justice, and education in Flanders participated in an online Delphi study. Qualitative analysis of answers in the first round yielded four definition possibilities that participants then ranked in the second round. In the last round, participants rated their agreement with the highest ranked definition. An additional survey asked 25 international experts to rate and comment their agreement with the final definition.

Results: The final definition was: Children and adolescents with profound and interacting needs in the context of issues on several life domains (family context, functioning and integration in society) as well as psychiatric problems. The extent of their needs exceeds the capacity (expertise and resources) of existing services and sequential interventions lead to discontinuous care delivery. As such, existing services do not adequately meet the needs of these youths and their families. Cross-sector, integrated and assertive care delivery is necessary for safeguarding the wellbeing, development and societal integration of these young people. Response rates to the three Delphi rounds were $76.6,89.1$, and $91.3 \%$. The definition was widely endorsed among Flemish (93.2\% agreement) and international experts (88\% agreement).

Conclusion: A definition of MCN in children and youth was constructed using the Delphi method and further evaluated for international relevance in an additional survey. Such an agreed-upon definition can be valuable for optimizing care delivery and conducting research.
\end{abstract}

Keywords: Delphi study; multiple and complex needs; definition; child serving agencies; children and adolescents

\section{Introduction}

A growing number of children and youth experience 'multiple and complex needs' (MCN) as a reflection of severe difficulties in different life domains $(1,2)$. This includes intertwined physical and mental health problems, social exclusion, educational issues, and for some justice involvement $(1,2)$.

The developmental impact of these problems puts their wellbeing and optimal integration into society at stake (3). This situation may lead to important societal costs due to extensive use of the health and social care and justice systems, as well as the potential compromise for academic and work outcomes $(2,4$ 6).

Experiencing these 'multiple' and 'complex' needs leads children and youth to engage in frequent contacts with professionals throughout different sectors of social and health care and justice $(4,7,8)$. Very often, this group experiences difficulties in getting adequate support, as no single agency or sector has all the resources, mandate, or reach to address both the personal needs of these vulnerable 
young people and their families and at the same time the social and economic factors that aggravate the complexity of these needs $(2,9)$. As a consequence of insufficient resources and capacities as well as poor integration and individualization of services (1, 10) these youth currently have long and fragmented care delivery trajectories, suffering the consequences of insufficiently coordinated referrals and sequential or parallel interventions by different services (11).

The lack of a common working definition of $\mathrm{MCN}$ hampers systematic understanding of the concept and greatly complicates efficient multi-agency care delivery for these children and youth $(2,4,12)$. Indeed, a plethora of terms are used to designate these 'multiple' and 'complex' problems in different health and social disciplines, most often unspecified and interchangeably (2). There is a tendency toward a narrow definitional lens, focusing on the problems presented by the youth from one professional perspective only, rather than seeing the interactional nature and context of the variables that cause cumulative harm. Another pitfall is to focus on the actual presenting problem on each occasion rather than to have a holistic perspective and response. These difficulties regarding care delivery contribute to what is referred to as 'complex' cases $(2,4)$.

There is a widely recognized and growing need for an expert endorsed definition of MCN in children and youth, both within and between the professional fields involved in the care for this population $(3,4)$.

This study aims to systematically construct an agreed-upon definition of MCN in children and youth utilizing the expertise of a multidisciplinary, cross-sector, and geographically spread sample of Flemish professionals. An additional survey evaluates international agreement with the resulting definition. Such an agreed-upon definition can contribute to optimizing care delivery for children and youth with MCN and their families

\section{Method}

\section{Setup}

The study reported in this paper is presented in two parts:

- Part 1: in a three round online Delphi survey (13), a consensus-based definition of $\mathrm{MCN}$ in children and youth was systematically constructed and assessed for agreement.

- Part 2: an additional survey evaluated the international level of agreement on construct validity for the final definition of the Delphi study in round 1.

\section{Part 1: Delphi study \\ Participants}

To achieve an agreed-upon definition of $\mathrm{MCN}$ in children and youth and given the fact that this population meets a wide variety of professionals in different fields, a cross-sector and multidisciplinary expert panel was recruited for this Delphi study, following sampling guidelines (13). The purposive sampling (14) was done via an initial email invitation sent to 53 experts. Experts were selected based on their expertise in and experience with $\mathrm{MCN}$ in children and youth and were working in the following fields:

1) youth mental health services; 2) youth care; 3 ) welfare; 4) juvenile justice; 5) services for disabled persons; and 6) education counseling.

In all, $47(89 \%)$ of invited experts agreed to participate. Geographical spread was ensured as experts from every province in the Dutch speaking part of Belgium (Flanders) were included in the sample.

Table 1 details some of the sample characteristics.

\section{Data collection}

In each round, all participants received a unique link to an online questionnaire in Qualtrics (Provo, Utah, version 3.8.0). Deadline for responding was set three to four weeks after the questionnaire was distributed and non-responders were sent reminder emails and contacted by phone. After each round, all participants received personalized feedback on their own answers and the panel's answers in the previous round.

- Round 1: Following the recommendations for classical Delphi studies $(14,15)$ the first round consisted of an open question. The question was: How would you, based on your vision and expertise, describe the population of children and youth with MCN?

- Round 2: In the second round, participants were asked to rank the four definition options that were formulated based on the analysis of round 1 . In an additional open question, participants could write down additions or changes they would make to the definition they ranked the highest.

- Round 3: In the third round, participants were asked to score their agreement with the definition that resulted from the second round, on a sixpoint Likert-scale.

\section{Data analysis}

Qualtrics (Provo, Utah) and Excel (Microsoft) assisted in data analysis.

- Round 1: The answers to the first round open question were analyzed following the sequence described for systematic text condensation (16). Three researchers followed the steps described in this approach of qualitative analysis:

- Reading the transcripts multiple times gave an 
overall impression and helped each of them to identify preliminary themes. Final themes were agreed upon after discussion between the three researchers.

- Each researcher identified text units, so-called units of meaning that characterize aspects to incorporate in the definition of $\mathrm{MCN}$ and coded for these.

- Researchers summarized the content of each code group into a condensate.

- Four definition possibilities were synthesized as an analytic text after reconceptualization of the data. Re-reading the original answers to the first-round question ensured goodness of fit with the final themes and code groups (16).

- Round 2: By weighing each position in the ranking order (attributing four points to the highest rank, three points to the second position, two points to the last but one and one point to the last position), the definition participants indicated as most fitting (the one with most points) was identified.

- Round 3: A priori, agreement was defined as a score of 4,5 or 6 on a six-point Likert scale (ranging from strongly disagree to strongly agree) evaluating the rate of agreement. Cut-off for consensus was defined at $75 \%$, in line with the literature (17). Moreover, the comments of all participants were reviewed, and following the preset cut-off, an addition or correction to the definition would be presented to the entire panel, if mentioned by at least $10 \%$ of the participants.

\section{Part 2: International survey Participants}

In a subsequent survey, an international perspective was sought on the definition that was constructed in the Delphi study. A total of 25 experts (response rate $33 \%$ ) originating from 11 different countries (UK, France, the Netherlands, Austria, Spain, Switzerland, USA, Canada, Australia, India, and Ecuador) rated and commented their individual agreement with the definition. Experts in MCN were sourced from their scientific publications and via professional societies: child and adolescent psychiatry (36\%), child psychology $(28 \%)$, social work $(20 \%)$, forensic psychiatry $(8 \%)$, children's nursing (4\%), and public policy (4\%). Moreover, all participants in the survey had a longstanding experience $(M=25.72$ years of professional experience in participating sample) with specific academic and practical expertise regarding MCN (56\% professor or associate professor, 16\% director/manager in youth care, $16 \%$ counselor/therapist, and $8 \%$ researcher).

TABLE 1. Expert panel of the Delphi study

\begin{tabular}{|c|c|c|c|c|}
\hline & $\begin{array}{c}\text { No. of } \\
\text { participants }\end{array}$ & $\begin{array}{l}\text { No. of responders } \\
\text { round } 1\end{array}$ & $\begin{array}{l}\text { No. of responders } \\
\text { round } 2\end{array}$ & $\begin{array}{l}\text { No. of responders } \\
\text { round } 3\end{array}$ \\
\hline \multicolumn{5}{|l|}{ Youth mental health } \\
\hline Policy & 3 & 2 & 3 & 3 \\
\hline CAP (hospital) psychiatrists & 8 & 3 & 7 & 7 \\
\hline CAP (hospital) psychologists & 3 & 3 & 3 & 3 \\
\hline $\begin{array}{l}\text { Mental health center child and adolescent } \\
\text { psychiatrist }\end{array}$ & 2 & 2 & 2 & 2 \\
\hline Mental health center psychotherapist & 1 & 1 & 0 & 0 \\
\hline \multicolumn{5}{|l|}{ Youth care } \\
\hline Policy & 5 & 4 & 5 & 5 \\
\hline (General) youth care & 9 & 7 & 8 & 9 \\
\hline Youth care for (presumed) Child abuse & 3 & 3 & 3 & 3 \\
\hline \multicolumn{5}{|l|}{ Welfare } \\
\hline Welfare centers for families & 1 & 1 & 1 & 1 \\
\hline General Welfare & 5 & 2 & 1 & 3 \\
\hline \multicolumn{5}{|l|}{ Juvenile justice } \\
\hline Juvenile judges & 2 & 2 & 1 & 2 \\
\hline Social workers in juvenile justice & 2 & 2 & 2 & 2 \\
\hline Professionals from juvenile justice & 2 & 2 & 2 & 1 \\
\hline \multicolumn{5}{|l|}{ Institutions } \\
\hline Services for persons with disabilities & 2 & 1 & 2 & 2 \\
\hline Education counseling & 1 & 1 & 1 & 1 \\
\hline Total & 47 & 36 & 41 & 42 \\
\hline
\end{tabular}




\section{Data collection}

Participants were asked to rate their agreement with the definition constructed in the Flemish Delphi study on a six-point Likert scale (ranging from strongly disagree to strongly agree) and were given the opportunity to comment on the definition.

\section{Data analysis}

In analogy with the Delphi study, score of 4,5 or 6 on the Likert scale were quantified as agreement.

\section{Results}

\section{Part 1: Delphi study}

\section{Participation}

Response rates were as follows: $73.5 \%$ for the first round, $85.4 \%$ for the second round, and $91.7 \%$ for the third round. In each round, each of the professional fields and every Flemish province were represented. Table 1 illustrates the number of participant responses in each round.

\section{Construction of the definition}

The main themes in the answers to the open question in round 1 were identified using systematic text condensation (16) and related to:

1) the issues pertaining to the children and youth themselves (the degree and the different affected life domains);

2) the role and efficacy of care delivery; and

3) the service needs of this population.

TABLE 2. Analysis of the answers to the first round open question

\begin{tabular}{|c|c|c|c|}
\hline Themes & Subthemes & Examples of codes & Definition aspects where different opinions existed \\
\hline Issues & $\begin{array}{l}\text { Severity, interrelation of } \\
\text { problems, domains affected }\end{array}$ & $\begin{array}{l}\text { 'Interrelation of problems,' } \\
\text { 'family problems,' 'psychiatric } \\
\text { problems' }\end{array}$ & $\begin{array}{l}\text { Family problems as a separate issue receiving separate } \\
\text { emphasis vs family problems not mentioned as a separate } \\
\text { entity }\end{array}$ \\
\hline $\begin{array}{l}\text { Care delivery } \\
\text { problems }\end{array}$ & $\begin{array}{l}\text { Fragmented care, incapacity } \\
\text { of actual care delivery to } \\
\text { cope }\end{array}$ & $\begin{array}{l}\text { 'Negative impact of } \\
\text { uncoordinated care,' 'services } \\
\text { overwhelmed' }\end{array}$ & $\begin{array}{l}\text { Inadequate/failing care delivery plays an important possibly } \\
\text { causal role vs inadequate care delivery not mentioned as } \\
\text { contributing to complexity }\end{array}$ \\
\hline $\begin{array}{l}\text { Care delivery } \\
\text { needs }\end{array}$ & $\begin{array}{l}\text { Different integrated services, } \\
\text { assertive approach }\end{array}$ & $\begin{array}{l}\text { 'Assertive care,' 'integrated care } \\
\text { provision by different sectors' }\end{array}$ & \\
\hline
\end{tabular}

After sorting the so-called 'meaning units' (text fragment containing relevant information) in the process of getting from themes to codes, definition possibilities were built in the condensation and synthetization steps of the process of systematic text condensation (16). Whereas these main themes suggested by all participants were very similar, differences emerged with regard to two aspects: first, the extent to which they viewed 'family context' problems as a separate and essential aspect of $\mathrm{MCN}$; and second, the (casual) role that is attributed to (inadequate) services with regard to complexity. Inserting the two possibilities for each of these two aspects of the definition, four different definition options were built.

The results from the analysis of round 1 are summarized in table 2 .

In the second round, participants ranked the four definition possibilities. The definition that was selected, received $20 \%$ more points (based on the ranking by participants) compared to the definition with the second highest amount of points.

\section{Definition and consensus Delphi study}

The final definition of MCN in children and youth was:

Children and adolescents with profound and interacting needs in the context of issues on several life domains (family context, functioning and integration in society) as well as psychiatric problems. The extent of their needs exceeds the capacity (expertise and resources) of existing services and sequential interventions lead to discontinuous care delivery. As such, existing services do not adequately meet the needs of these youths and their families. Cross-sector, integrated and assertive care delivery is necessary for safeguarding the wellbeing, development and societal integration of these young people.

There was a high consensus rate for this final definition, as $93.2 \%$ of the participants agreed it. Approximately $35 \%$ of the participants made an 
additional comment in round 2, regarding the definition ranked highest. However, each of these ideas was mentioned by less than $10 \%$ of the experts and consequently the definition was kept as formulated in the second round.

Participants suggested: 1) that physical problems/biological/medical domain should be emphasized specifically in the definition $(n=4) ; 2)$ to specify certain aspects ('school problems' $(n=1)$, at risk of unemployment' $(n=1)$, 'parents with psychiatric illness' $(n=1)$, 'parents in a (temporary) difficult psychosocial situation $(n=1))$ 'behavior' ( $n$ $=1$ ) as suggestions to be mentioned separately in the definition; 3) to add '[...]' between brackets after 'integration in society' to show that list is not limited to this suggested replacing 'safeguarding' with 'stimulating' ( $n=1)$; 4) to complete the last sentence (regarding services) with: 'as to prevent discontinuity' $(n=1)$, 'starting from a shared vision with youths and parents' ( $n=1)$, high intensity of treatment needed $(n=1)$, 'multidisciplinary' $(n=1)$; and 5$)$ that the definition is complete and/or should not be longer $(n=4)$.

\section{Part 2: International survey Participation}

A total of 25 international experts (response rate $33 \%$ ) rated their agreement with the definition that was developed during the Delphi study. In total, 88 percent of these international experts agreed with the definition and gave scores 4 and above on a six-point Likert scale $(\mathrm{M}=4.6, \mathrm{SD}=1.2 ; \mathrm{Mdn}=5)$. A total of 60 percent of the international experts made an additional comment. These revolved around: 1) the inclusion of the aspect of problems of the child/adolescent as well as the shortcomings of services. This was viewed by some as very positive, as they highlighted how a mismatch between services or needs/failing services are part of the cumulative harm $(n=4)$. Others indicated they would not include this in the definition $(n=4) ; 2)$ the terminology 'psychiatric problems' was criticized/replaced by 'mental health' $(n=3)$, or too much emphasis was placed on the psychiatric aspect in the definition $(n=2)$; 3) suggestions to specify some aspects: 'detail psychiatric problems: behavior, attachment, [...]' $(n=1)$, 'frequent history of trauma' $(n=1)$, 'family problems' $(n=1)$ 'high-risk or criminal behavior' $(n=2)$,' financial problems' $(n=$ $1)$, 'difficulties in access services due to remoteness' $(n=1)$, 'school problems' $(n=2)$ and 'work problems' $(n=1)$; 4) suggested to specify 'existing services working alone' rather than 'existing services' $(n=1) ; 5)$ to replace 'profound' by 'severe' $(n=1)$; and 6$)$ the definition is too long and/or complex (n $=2$ ).

\section{Discussion}

Current research does not offer a common definition of MCN in children and youth to the variety of professionals working with this population. This compromises understanding of service delivery, risks patient outcomes, and research validity. In a threeround Delphi study, a definition of MCN in children and youth was systematically constructed based on the contributions of a multidisciplinary and crosssector panel of experts in child and youth serving agencies in Flanders. The definition constructed in the Delphi study was widely endorsed, as reflected by the high consensus rate amongst Flemish experts $(93.2 \%)$ and the fact that a large proportion of international experts $(88 \%)$ also expressed their agreement.

The hope is that such an agreed-upon definition could help the development and implementation of services that more effectively respond to the needs of children and youth with MCN and their families. Having a common definition could optimize communication, coordination, and exchange between professionals on the case level, and inform policy makers on priorities in developing (collaborative) programs and allocating resources. A common language is important for research, in order to collect and use epidemiological data or to evaluate programs effectively.

A potential limitation of this Delphi study is the limited generalizability across diverse settings. The fact that only Flemish experts were included in the Delphi study may have resulted in local factors (such as specificities of the youth care or mental health organization) influencing the final definition. The inclusion of experts from every province ensured the relevance of our findings for the whole of Flanders. Such an approach has its use in order to inform and adapt local care delivery programs but may not yield a definition that is useful to professionals working in different settings. However, the fact that international experts in the field who have academic as well as practice experience agreed with the definition_at least to some extent, suggests that it could be useful in a wider context.

Strength of this study is the fact that the Delphi study had high response rates and was conducted with a heterogeneous and geographically spread sample of qualified experts throughout the relevant fields for vulnerable children and youth. The survey with highly experienced international experts not only provided an international perspective regarding agreement rates, but also raised interesting topics for reflection.

\section{Definition compared to the literature}

The definition of MCN in children and youth that was constructed in this Delphi study is largely in line 
with the concepts scattered in social and health literature describing MCN. Elements of the definition that are similar to the literature are: 1) the dimensions of severity ('depth') as well as interrelatedness ('breadth') of issues are important in determining the complexity; and 2) the role of services in complexity, and the need for services to collaborate $(2,18)$. However, the physical conditions that are often mentioned in the literature about vulnerable children and youth with multiple needs were not included as an element of the definition in this Delphi study.

The needs of children and youth with $\mathrm{MCN}$ are characterized by the participating experts as being profound as well as interacting on several life domains. The fact that complexity in needs revolves around severity, as well as the interrelatedness of issues is described in terms of 'depth' (severity) and 'breadth' (affecting several domains) in earlier reports (18). The degree of severity of one issue can create a considerable challenge for the service system, but the fact that a multitude of issues exists is even more daunting, as it is the interaction of risks that produces the most harmful effects $(4,19)$. Considering the breadth of issues, it is important to look beyond a narrow definitional vision limited to each sector's specific expertise, and to have sufficient attention for aspects relating to functioning and participating in society and ordinary life $(2,20)$. In line with this idea is the recommendation to use a definition for MCN is non-categorical in that it does not assign the responsibility to one single sector or discipline but rather acknowledges the fact that needs may arise from a number of different conditions and that focuses on the interrelatedness of issues (20).

Besides pointing out the difficulties of these young people and their relatives, the definition developed in this study also highlights the mismatch between the needs of these families, and the fragmented care delivery they may experience. The perspective that the needs of these populations at the extreme of a spectrum of case complexity overwhelm the resources, mandate or possibilities of individual professionals or agencies is also endorsed in the literature $(1,4)$. Even when individual services are providing high-quality care, the varied, specialized and changing needs of children and youth with $\mathrm{MCN}$, ask for cross-sector resources and expertise, with a focus on continuity of care.

Some authors define the population of youths as high risk due to the fact that their individual characteristics (e.g. behavioral issues) conflict with the system characteristic such as high caseloads and reactive casework. That conflict results in care delivery that does not meet the needs of these complex cases, and professionals who are overwhelmed and feeling helpless (21). Others take this idea one step further and take the shortcomings of care delivery, rather than the individual problems, as a starting point and argue that complexity arises due to the failure of services to meet needs adequately (22). In that prospect, the person's needs are not necessarily complex, but it is the challenge in coordinating all different services that people with MCN need across the various sectors that creates complexity (23). As such, complexity is by some authors considered to originate in the eye of the beholder, referring to the fact that skills and resources of professionals affect how 'complex' a child's issues and circumstances are considered to be (22).

The definition constructed in this Delphi study highlights the importance of an integrated care delivery approach and as such is in line with literature recommendations pointing out the importance of intensive interagency and cross-sector collaboration including shared goals, accountability strategies, and outcome evaluation. Indeed, adequately meeting the needs of this population requires all professionals to work collaboratively and join resources to achieve common goals: ensuring a safe and caring environment with consistent structure and routine, emotional containment and support, and planned specialized responses to behaviors and emotions (22). Several authors point out that limited communication and coordination of services across sectors is not sufficient to ensure that the needs of youth with MCN are adequately addressed, arguing the critical importance of integrated care; particularly mental health, justice, and child welfare. They argue that it is critical to fully integrate services such as mental health, juvenile justice, child welfare, and substance abuse as a means of improving measurable outcomes for the most vulnerable children (24). The idea that more complex cases require stepping up on the collaboration spectrum is widely endorsed in the broader literature on interagency collaboration (25, 26).

A divergence when comparing the definition in this Delphi study with the available literature is the fact that physical problems or risks were not explicated in the definition constructed by the expert panel in this study. However, numerous accounts in the literature highlight how in vulnerable populations of children and youth, physical and psychosocial difficulties are strongly related and reinforce each other (27). Possibly, these experts do not view the physical problems as condition sine qua non (absolutely necessary) in order to classify a case as MCN. Alternatively, this could be related to the fact that most of the expert panel did not work in a medical setting. Either way, considering the frequency of physical problems in vulnerable youths (28), it is important to be attentive to them when evaluating 
children and youth with MCN.

\section{Reflection on experts' comments}

None of the suggested changes or additions that experts made after the second Delphi round exceeded the a priori threshold to be presented to all participants.

Regarding the survey, following the suggestions of the international experts could lead us to a further adaptation of the definition:

1) replacing psychiatric problems by mental health issues, due to the fact that psychiatric problems is too narrow as a term, or too definitive of psychiatric pathology and can have different significance in different countries; and

2) adding 'individual' services in order to put less emphasis on the fact that current services fail and put more emphasis on the potential of collaborating.

Other issues were more contested. While some international participants stressed the importance of having both the child issues and the failure of services or the failure to access services in the definition, others indicated they would not include any information on services or their capacity to cope in a definition. As described above, this disparity also exists in the literature.

In our opinion, while neither generalization nor determination of a causal link is possible, fragmented care delivery and many referrals could be important in the cumulative harm experienced by these children and youth and warrants attention when evaluating their needs and planning services.

\section{Clinical significance}

In Flanders, where this definition was constructed based on the inputs of a variety of experts in the care for children and youth with MCN, these results could guide definitive understandings of $\mathrm{MCN}$, practice, and policy. In the evaluation of the needs of children and youth with MCN, the different aspects mentioned by these clinical experts should all (at once) be taken into account: mental health, integration, and participation in society, family, and broader social context. This calls upon a multidisciplinary problem evaluation. There should also be attention for the accessibility of services and the aim should be to provide a holistic support addressing the different needs and focusing on continuity of care.

Different ideas for broader practice and research can be derived from the resulting definition of $\mathrm{MCN}$ in children and youth. For practitioners evaluating families and planning services for individual cases, it seems important to keep in mind that both the severity of issues and the fact that they occur on different life domains are important contributors to complexity, and consequently both aspects should be evaluated and addressed. In evaluation of services, an open and collaborative professional attitude seems especially important for this vulnerable population.

Finding a common language and exchanging information on individual cases, as well as broader expertise between professionals, can make significant changes for individual cases and can be valuable for professionals too. On the policy level, investing in cross-sector coordination and optimizing service accessibility and responsiveness to MCN would make an important contribution to care delivery for children and youth with MCN.

Future research utilizing an international Delphi study would be valuable to construct an international consensus on a definition of MCN. The perspectives of children and youth, and families with MCN would be immensely valuable to future MCN definition research.

\section{Ethics}

This research project was approved by the ethics committee of the University of Antwerp/University hospital Antwerp. All potential participants received written information and had the opportunity to address further questions to the research team. All participants gave their informed consent prior to participation.

\section{Conflicts of interest}

The authors declare no conflicts of interest.

\section{References}

1. Keene J. Clients with complex needs: interprofessional practice. Oxford: Blackwell Science Ltd; 2001.

2. Rosengard A, Laing I, Ridley J, Hunter S. A literature review on multiple and complex needs; 2007. Available from: www.scotland.gov.uk/socialresearch

3. Stalker K, Carpenter J, Phillips R, Connors C, MacDonald C, EyreJ, et al. Children with complex support needs in healthcare settings for long periods. York: Joseph Rowntree Foundation, Pavilion Publishing; 2003.

4. Burnside L. Youth in care with complex needs. Special report for the Office of the Children's Advocate. Alberta; 2012.

5. Leve LD, Chamberlain P. Female juvenile offenders: defining an early-onset pathway for delinquency. J Child Fam Stud 2004;13(4):439-52.

6. Grisso T. Adolescent offenders with mental disorders. Future Child 2008;18(2):143-64.

7. Zachik AA, Naylor MW, Klaehn RL. Child and adolescent psychiatry leadership in public mental health, child welfare, and developmental disabilities agencies. Child Adolesc Psychiatr Clin North Am 2010;19:47-61.

8. Thoburn J. Effective interventions for complex families where there are concerns about, or evidence of, a child suffering significant harm. London; 2009 [working paper]. 
9. Walker S. Interprofessional work in child and adolescent mental health services. Emot Behav Diffic 2003;8(3):189-204.

10. Fay Mitchell P. Designing evidence-based treatments for youth with multiple and complex needs: a modular practice elements approach. Adv DualDiagn 2012;5(3):122-36.

11. Katz I, Spooner C, Valentine K. What interventions are effective in improving outcomes for children of families with multiple and complex problems? West Perth, WA: Australian Research Alliance for Children \& Youth; 2006

12. Horwath J, Morrison T. Collaboration, integration and change in children's services: critical issues and key ingredients. Child Abuse Negl 2007;31(1):55-69.

13. Shelton K, Haynes CA, Creghan KA. Fundamentals of Delphi research methodology. In: VCX Wang, TG Reio, Jr. (Eds). Handbook of research on innovative techniques, trends, and analysis for optimized research methods. Hershey, PA: Information Science Reference 2017; 233-57.

14. Trevelyan EG, Robinson N. Delphi methodology in health research: how todo it? Eur J Integr Med. 2015;7:423-8.

15. Brady SR. Utilizing and adapting the Delphi method for use in qualitative research. Int J Qual Methods 2015;14(5):1-6.

16. Malterud K. Systematic text condensation: a strategy for qualitative analysis. Scand J Public Health 2012;40(8):795-805.

17. Diamond IR, Grant RC, Feldman BM, Pencharz PB, Ling SC, Moore AM, et al. Defining consensus: A systematic review recommends methodologic criteria for reporting of Delphi studies. J Clin Epidemiol 2014;67(4):401-9.

18. Rankin J, Regan S. Meeting complex needs: the future of socialcare; $2004 . \quad$ Available from: https://www.ippr.org/research/publications/meeting-complexneedsthe-future-of-social-care

19. McLaughlin KA, Green JG, Gruber MJ, Sampson NA, Zaslavsky AM, Kessler RC. Childhood adversities and adult psychiatric disorders in the National Comorbidity Survey Replication II: associations with persistence of DSM-IV disorders. Arch Gen Psychiatry 2010;67(2):124-32.

20. Schmied V, Brownhill S, Walsh P. Models of service delivery and interventions for children and young people with high needs. Ashfield, New South Wales: Centre for Parenting \& Research; 2006.

21. Smyth P, Eaton-Erickson A. Making the connection: strategies for working with high-risk youth. In: S McKay, D Fuchs, I Brown (Eds). Passion for action in child and family services: voices from the prairies. Regina, SK: Canadian Plains Research Center; 2009, pp. 119-42. Available from: https://cwrp.ca/publications/makingconnection-strategies-working-high-risk-youth

22. Rich J. Labels that disable: meeting the complex needs of children in residential care. Available from: https://www.nice.org.uk/guidance/ph28/evidence/ep14-labelsthat-disable-meeting-the-complex-needs-of-children-in-residentialcare-janet-rich-pdf-430122925

23. Richard B, Smallwood S. Staying connected: a report of the task force on a centre of excellence for children and youth with complex needs. Fredericton, New Brunswick: The Office of the Ombudsman and Child and Youth Advocate; 2011.

24. Hornberger S, Martin T, Collins J. Integrating systems of care: improving quality of care for the most vulnerable children and families. Washington, D.C.: CWLA press; 2007; 1-5.

25. Seaburn DB, Lorenz AD, Gunn WB, Jr., Gawinski BA, Mauksch LB. Models of collaboration: a guide for mental health professionals working with health care practitioners. New York: Basic Books; 1996:145-58.
26. Cooper M, Evans Y, Pybis J. Interagency collaboration in children andyoung people's mental health: a systematic review of outcomes, facilitating factors and inhibiting factors. Child Care Health Dev 2016;42(3):325-42.

27. Nelson TD, Smith TR, Hurley KD, Epstein MH, Thompson RW, Tonniges TF. Association between psychopathology and physical health problems among youth in residential treatment. J Emot Behav Disord, 2012;21(2):150-60.

28. Nelson TD, Smith TR, Thompson RW, Epstein MH, Griffith AK, Hurley KD, et al. Prevalence of physical health problems among youth entering residential treatment. Pediatrics 2011;128(5):e122632. 